\section{COMMONWEALTH OF AUSTRALIA COUNCIL FOR SCIENTIFIC AND INDUSTRIAL RESEARCH}

\section{ANNUAL REPORT}

$\mathrm{T}$ HE nineteenth annual report of the Council for Scientific and Industrial Research, Commonwealth of Australia, covers the year ended June 30, 1945 , and indicates the greater attention which was given to problems of post-war reconstruction, as, for example, in the use of the Soils Division's surveys of areas intended for closer settlement (Canberra : Commonwealth Gov. Printer). The report also refers for the first time to the Division of Radiophysies, which with its central laboratory at the University of Sydney was formed early in the War, and until the termination of hostilities was engaged solely on work for the Australian and American Fighting Services. In addition to representatives of the Australian Fighting Services, the Radiophysics Advisory Board included representatives of the Postmaster-General's Department and, later, of the Ministry of Munitions, while effective liaison was also established with Great Britain and the United States through the British Central Scientific Office at Washington. In addition to assisting the Services very considerably in technical training courses and facilities, the Division has been engaged in fundamental research associated with the design of radar equip. ment and in the investigation, development, design and manufacture to the prototype stage of radar and associated equipment required by the Armed Forces. A light-weight radar set was designed and constructed for the Royal Australian Air Force for air warning purposes, and in addition to investigations into the cause and incidence of super-refraction at relatively low heights in the atmosphere and ionospheric observations, the Laboratory has now initiated some work on possible applications in the field of navigational aids for civil aviation.

In addition to the account of the formation and work of this new Division, the report refers also to the conversion of three sections of the National Standards Laboratory to the status of Divisions of Metrology, of Electrotechnology and of Physics, respectively, while the former Division of Animal Health and Nutrition has been separated into two divisions, known as the Division of Animal Health and Production and the Division of Biochemistry and General Nutrition.

An important development during the year was the decision to undertake a comprehensive programme of research into building materials, including concrete and other materials for structures such as bridges, dams, etc. The Council has also accepted responsibility for work on flax processing, and is to be entrusted with an extensive programme of research and publicity for the wool industry; while as from April 16, 1945, the Council has taken over the Scientific Liaison Bureau.

Under the Division of Plant Industry, a laboratory for the study of pasture production under irrigation is being established in the area between the Murray and the Murrumbidgee Rivers, while other pasture investigations were concerned with pasture management, soil fertility, the establishment of pasture under cover crop, the control of Capeweed and other weeds. The Division also conducted trials of plants and seeds introduced from abroad, forage and pasture plant trials, as well as investigations on Guayule rubber, take-all disease of wheat, native plants as sources of medicinal drugs and insecticidal substances, the opium alkaloids, tobacco, the potato virus and varietal resistance to leaf roll, spotted wilt and fusarium wilt of tomato, the retting of flax, etc. Investigations on the physiological diseases of apples and pears were on a much reduced scale; but in the entomological field the outstanding feature was the attention given to the new insecticides D.D.T. and 666. A large-scale programme of investigation on the use of D.D.T. for the control of agricultural and horticultural pests was carried out in co-operation with all the State Departments of Agriculture, and particularly promising results were obtained in the control of cattle tick, buffalo fly and certain household pests. Methods for the control of mosquitoes and house flies reached an advanced stage of development, and investigation of the pests of stored wheat was practically concluded with the development of effective measures for the control of infestations in the main types of temporary stores. Much success in particular attended the campaign, based on the Council's advice, against wheat weevil carried out by the Australian Wheat Board; while the work on the biological control of weeds and insect pests continued to show great promise; for example, that of St. John's wort by three species of Hypericum insects. Work on D.D.T. emulsions led to the development of a solvent naphtha emulsion which was used in field trials in $1944-45$, mainly at $0 \cdot 2$ per cent D.D.T., and work on the control of cattle ticks included trials with D.D.T. sprays.

Animal health investigations covered pleuro. pneumonia of cattle, mastitis in dairy cattle, contagious abortion of cattle, and the bacterial oxidation of arsenic cattle-dipping fluids. Studies with phenothiazine continued, as well as investigations of the blowfly strike problem and biochemical studies on mineral metabolism of sheep. There was no break in the sequence of the long-term research projects concerned with the nutrition of the Merino sheep, and the results should now provide a rational basis for breeding policy. Drought feeding and metabolic studies, the supply of vitamin A to flocks during prolonged periods of drought, the study of the plant proteins which are the raw materials from which the sheep produces wool fleece, studies of minor element deficiencies, and especially copper deficiency, are other directions in which the Council is assisting this major Australian industry.

The Division of Soils continued with a wide programme of surveys and investigations, and the obstacle to rapid progress presented by the lack of experienced staff is now being removed by the training of new personnel. Field-work was turning increasingly to the relation of soils and land use. The Soil Chemistry Section, organised jointly with the Chemistry Department of the Waite Institute under single direction, devoted attention to the study of methods for the examination of soils, including the use of the Lundegådh flame spectrum technique for the determination of exchangeable cations. The study of soil structure and water relations of soils formed the main activity of the Soil Physics and Mechanics Section, while in the Bacteriology Section the investigation of the nitrogen-fixing organisms of leguminous plants was the main line of research.

At the Commonwealth Research Station, Merbein, initial investigations on vegetable production were completed, particularly variety trials of tomatoes, 
beans and carrots, while at the Irrigation Research Station, Griffith, work on the best methods of irrigation of both orchard and vegetable crops continued. Much of the work of the Division of Forest Products was again associated with the war effort; but the need for a more concentrated examination of timber utilization in Australia is recognized, and a series of lectures was prepared for a reconstruction training course for Service personnel proposing to enter the building trade. Wood structure, timber physics and mechanics, timber preservation and seasoning continued to receive attention, as well as the improvement of wood, particularly by gluing or impregnation with dimethylolurea.

The Food Preservation Division is to resume its investigations on the preparation and storage of chilled beef with particular attention to the loss of bloom, and work is also to be started on the rapid freezing of fruit and vegetables. Fundamental aspects of the metabolism of ripening and senescence of fruits were examined at the University of Sydney. Apparatus was designed for measuring the vapour pressure of dried foods, and heat transfer and evaporation from a wet surface under still air conditions ; investigations on Clostridium botulinium and on the resistance of this and other bacterial spores to heat were continued. The relation between mould growth and the activity of water in fruit cake, the development of ascorbic acid in processed foods on prolonged storage and fundamental studies on the oxidation of ascorbic acid in fruit and vegetable tissue suspensions were initiated. The Division of Fisheries was able to expand its work somewhat.

The Division of Metrology continued to assist production directorates of the Ministry of Munitions and industrial organisations concerned with defence, in matters relating to inspection, design and examination of gauges, measuring equipment and precision tool-room equipment. The Division of Electrotechnology concentrated largely on confidential defence investigations, but is now considering the resumption of normal work. Its future programme is likely to be influenced by the recent formation of an Electrical Research Board. The programme of research on tropic proofing and the scope of climatic and durability tests on telecommunication materials and communications have been considerably extended. The Physics Division is also planning to extend its long-range and fundamental research; among work carried out during 1944-45 were studies of the optimum visual conditions for radar operators, the photometry of a new type of searchlight, the control and measurement of humidity in connexion with tropic proofing of service equipment, the design of an instrument for the accurate and rapid measurement of hæmoglobin for 'blood bank' work, and fundamental work on the physics of wool fibres. Aeronautical investigations have included studies of the effects of turbulence on the size, state and stability of the boundary layer formed on the surface of solid bodies moving through air, the strength and stability of plywood construction, a mathematical study of the vibration characteristics of an engine-propeller-cooling-fan combination, powder metallurgy, welding of steel tubing and fatigue failures.

In the Division of Industrial Chemistry, a Section of Chemical Physics has been established at Melbourne. The Minerals Utilization Section has perfected a method for the production of the special grade of rare-earth oxides required for polishing optical lenses and prisms. The Cement Section is investigating the deterioration of concrete through expansive reaction between aggregates and cement, and in the Biochemistry Section the development of depilatory paints less harmful to wool than the limesulphide paint now used, the wool-loosening action of ammonia, proteolytic enzymes and the production of $2: 3$-butylene glycol by fermentation have received attention. The separation of minerals by flotation, physico-chemical characteristics of acridine drugs and surface areas of solids have been studied by the Physical Chemistry Section. The Organic Chemistry Section was also concerned with the production of butadiene from 2:3-butylene glycol obtained by fermentation, and continued work on the exudation of mannitol from Myoporum platycarpum, synthetic resin adhesives and aniline-formaldehyde resins. In the Chemical Engineering Section pilot-plant trials were conducted of the Fremey-Lipson process rendering woollen goods resistant to felt, and of an improved process for the manufacture of rare-earth hydroxides from monazite. The general basic attack on problems associated with friction, lubrication, bearings and wear continued, including the mechanism of boundary lubrication, effect of abrasives on wear, the development of a soluble extreme-pressure cutting and drawing lubricant, the lubrication between $\mathbf{a}$ journal and a bearing and the behaviour of pure metals.

\section{THE GEOMETRY OF NUMBERS}

$T$

HE meeting of the London Mathematical Society on December 19, 1946, took the form of a symposium on the geometry of numbers, arranged by Prof. H. Davenport. Prof. E. C. Titchmarsh, president of the Society, was in the chair.

In his introductory remarks, Prof. Davenport outlined the nature of the subject. It consists in interpreting geometrically questions in the theory of numbers, making use of points with integral co-ordinates, either in the plane, or, more generally, in an $n$-dimensional space. The system of all points with integral co-ordinates is called the standard lattice. The general homogeneous linear transformation, or affine transformation, of the standard lattice gives a general lattice. Thus the points of a general lattice in $n$-dimensional space are the points $\left(x_{1}, \ldots\right.$, $x_{n}$ ), where $x_{1}, \ldots, x_{n}$ are linear forms:

$$
\begin{aligned}
& x_{1}=a_{11} u_{1}+\ldots+a_{1 n} u_{n} \\
& \ldots \ldots \ldots \ldots+a_{n n} u_{n}
\end{aligned}
$$

in $n$ variables $u_{1}, \ldots, u_{n}$, which take all integral values. The determinant of the coefficients $a_{i j}$ is called the determinant of the lattice, and measures the density with which the lattice points are dis. tributed in space (the density being inversely pro. portional to the determinant).

Many questions in the theory of numbers can be expressed in the form : Does a particular region contain a lattice point, or under what conditions is this the case ? This geometrical approach led Minkowski to many important theorems. It is also valuable in suggesting new and interesting questions, even when it does not provide any means for answer. ing them. Two of the three topics discussed later are, in fact, treated by other methods.

Mr. C. A. Rogers spoke on his recent work ${ }^{1}$ on a theorem of Hlawka. This theorem is a partial con- 